\title{
CONHECENDO O ESPAÇO VIVIDO ATRAVÉS DA CARTOGRAFIA \\ ESCOLAR
}

\section{KNOWING THE AREA SCHOOL LIVED THROUGH MAPPING}

\author{
Viviane Paiva dos Santos \\ Universidade Estadual da Paraíba \\ vivy.paivah@gmail.com \\ Josandra Araújo Barreto de Melo \\ Universidade Estadual da Paraíba \\ ajosandra@yahoo.com.br
}

\begin{abstract}
RESUMO
Este trabalho descreve e analisa as atividades desenvolvidas através do projeto de intervenção/colaboração desenvolvido no âmbito do Programa Institucional de Bolsas de Iniciação à Docência - PIBID/CAPES/UEPB, realizado na Escola Estadual de Ensino Médio Inovador e Profissionalizante Hortênsio de Sousa Ribeiro (PREMEN), Campina Grande-PB, que teve como objetivo principal proporcionar aos alunos formas de conhecimento do espaço vivido e interpretá-lo através da cartografia. O intuito foi desenvolver o conhecimento cartográfico dos alunos, visando usar o espaço vivido como ferramenta, ou seja, mapear a cidade através da percepção dos mesmos. A partir da realização da atividade, foi possível observar o interesse dos alunos pela temática e a curiosidade dos discentes pelo conhecimento dos espaços da cidade em que vivem. $\mathrm{O}$ resultado alcançado com estas atividades confirmou que trabalhar com a realidade dos alunos usando diferentes metodologias, incentiva o interesse pela construção do conhecimento.
\end{abstract}

Palavras-Chave: Ensino de Geografia; Cartografia; Espaço vivido.

\begin{abstract}
This paper describes and analyzes the activities developed through the intervention/ collaboration project developed under the Scholarship Program of Introduction to Teaching - PIBID/CAPES/UEPB, held at the State High School Vocational and Innovative Hortênsio de Sousa Ribeiro (PREMEN), Campina Grande-PB, which aimed to provide students with knowledge of the forms of lived space and interpret it through cartography. The aim was to develop the cartographic knowledge of students, aiming to use the tool as a lived space, ie, mapping the city through the perception of the same. From the day of activity, we observed students' interest in the topic and the curiosity of students by knowledge of city spaces in which they live. The results obtained with these activities confirmed to work with the reality of students using different methodologies, encourages interest in the construction of knowledge.
\end{abstract}

Keywords: Teaching Geography; Cartography; Lived Space. 


\section{INTRODUÇÃ̃O}

Quando se reflete sobre o ensino de Geografia nas escolas atualmente, logo se percebe o quanto este se encontra desvalorizado, muitos veem a referida disciplina apenas como um componente utilizado apenas como ferramenta para descrição do mundo (LACOSTE, 2010, p.20). Mas, de fato, seria esta disciplina algo cansativo, cuja única importância seria conhecer o espaço em que vivemos? Apenas a titulo de informação. Mas que serventia tem estas informações, a princípio tão relevantes?

Ao se discutir a função/papel da Geografia, várias respostas surgiram para estas perguntas. Cabe aos professores da disciplina mostrar o verdadeiro significado e valor do componente curricular, sobretudo quanto à possibilidade de compreensão do mundo vivido. É preciso mostrar que ela está presente em seu cotidiano, no seu dia-a-dia.

Algumas vezes, o conhecimento geográfico é repassado aos alunos, como algo sem aplicabilidade fora da escola. Por isso, após terminar o secundário, os alunos não compreendem a importância que a Geografia tem fora do ensino e não são capazes de ver como a mesma está presente no seu cotidiano, e como isto diretamente ou indiretamente afeta sua história. Segundo Pontuschka et al. (2009):

A Geografia, como disciplina escolar, oferece sua contribuição para que alunos e professores enriqueçam suas representações sociais e seu conhecimento sobre as múltiplas dimensões da realidade social, natural e histórica, entendendo melhor o mundo em seu processo ininterrupto de transformação, o momento atual da chamada mundialização da economia (ibidem, p. 39).

Portanto, é preciso procurar a raiz do problema, entender os motivos da falta de interesse dos alunos e buscar possíveis soluções. Tendo em vista tal compreensão, a presente intervenção/colaboração com a utilização da cartografia e geopolítica do espaço vivido dos alunos partiu da compreensão de que é de suma importância desenvolver no ensino diferentes metodologias, visando melhorar a participação dos alunos nas aulas e possibilitar a aproximação do conteúdo visto na sala de aula com o cotidiano dos alunos. A cartografia contém propriedades que, junto à realidade cotidiana dos alunos, tornam-se um valioso instrumento no desenvolvimento da capacidade de interpretação, compreensão, análise, expressão de ideias, construção de conhecimento e mudança de atitudes. De acordo com os Parâmetros Curriculares Nacionais:

Geo UERJ. Rio de Janeiro - Ano 16, no. 25, v.2, $2^{\circ}$ semestre de 2014, pp.108-121

ISSN: 1415-7543 E-ISSN: 1981-9021

http://www.e-publicacoes.uerj.br/index.php/geouerj 
A Geografia tem por objetivo estudar as relações entre o processo histórico na formação das sociedades humanas e o funcionamento da natureza por meio da leitura do lugar, do território, a partir de sua paisagem. Na busca dessa abordagem relacional, trabalha com diferentes noções espaciais e temporais, bem como com os fenômenos sociais, culturais e naturais característicos de cada paisagem, para permitir uma compreensão processual e dinâmica de sua constituição, para identificar aquilo que na paisagem representa as heranças das sucessivas relações no tempo entre a sociedade e a natureza em sua interação. (BRASIL, 2011, p.26)

Nesta perspectiva, espera-se que através desta iniciativa possa-se facilitar o aprendizado dos alunos em relação à interpretação e construção de mapas, levando-os a relacionar seu espaço vivido, cartografia e a ciência geográfica. Além disso, perante os desafios encontrados no ensino atual, se tornam necessários estudos acerca de metodologias que possibilitem a inserção do aluno no processo de construção do saber. Diante desses desafios, foi proposto um maior/melhor trabalho acerca da cartografia e geopolítica da cidade de Campina Grande, fragmentado através dos seus bairros.

A partir do exposto, foi realizada uma pesquisa empírica e, no decorrer do último bimestre escolar de 2012, colocada em prática esta proposta, desenvolvida na Escola Estadual de Ensino Médio Inovador e Profissionalizante Hortênsio de Sousa Ribeiro (PREMEN), nas turmas do "3" ano E" e "3" ano F" do Ensino Médio, cumprindo exigências do projeto PIBID/CAPES/UEPB, Subprojeto de Geografia, que tem como finalidade proporcionar aos estudantes de licenciatura a inserção no ambiente escolar e, a partir disto, que estes desenvolvem projetos de intervenção/colaboração nas aulas dos professores, a partir de um diagnóstico das principais lacunas identificadas no ensino-aprendizagem de Geografia, possibilitando um diferencial no ensino e auxiliando o professor com diferentes metodologias e uso de recursos didáticos.

O projeto de intervenção implementado nas turmas teve como objetivo geral que o aluno interpretasse o seu espaço, representando/codificando segundo a sua percepção. Como objetivos específicos buscou-se relacionar os conhecimentos cartográficos ao conteúdo da Geopolítica; debater a construção de ordens mundiais e seus reflexos em múltiplas escalas; abordar o contexto de desordem mundial nas dimensões política e econômica, bem como seus rebatimentos no cotidiano discente. 
Mediante o exposto, este artigo tem por objetivo principal analisar as experiências do projeto de intervenção/colaboração desenvolvido no âmbito do Programa Institucional de Bolsas de Iniciação à Docência - PIBID/CAPES/UEPB.

\section{METODOLOGIA}

\subsection{Contextualização e caracterização do objeto de investigação}

O projeto desenvolvido faz parte das atividades propostas pelo Subprojeto de Geografia, integrante do PIBID/CAPES/UEPB, dentre as quais o bolsista tem como tarefa intervir de forma participativa nas aulas do professor supervisor, colaborando para que inove suas aulas, através de diferentes metodologias e recursos didáticos. Após conhecer os anseios, opiniões e sugestões da(s) turma(s) deve-se, junto ao professor supervisor, desenvolver um projeto de intervenção/colaboração. O ambiente escolhido para o desenvolvimento destas atividades foi a Escola Estadual de Ensino Médio Inovador e Profissionalizante Dr. Hortênsio de Sousa Ribeiro (PREMEN).

Esta escola atualmente contempla atividades do Ensino Médio Inovador e, embora tenha um bom espaço físico, ainda necessita de algumas infraestruturas para atender melhor, visto que conta com um grande número de estudantes, aproximadamente 863 , distribuídos em cerca de 20 salas, nos turnos manhã e tarde. A escola também dispõe de sala de vídeo, informática e os laboratórios de química e biologia que, em 2012, eram usadas como sala de aula, mas este ano (2013) voltaram a ter suas reais funcionalidades. A escola também possui um corpo docente com cerca de 36 professores. As Figuras 1 e 2 apresentam aspectos da estrutura física da escola.

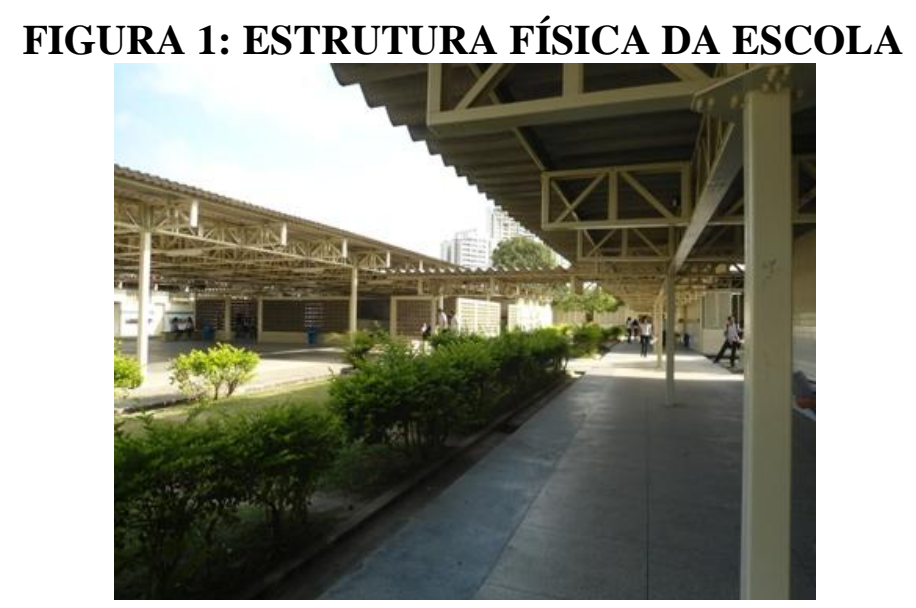

Geo UERJ. Rio de Janeiro - Ano 16, no . 25, v.2, $2^{\text {o }}$ semestre de 2014, pp.108-121 ISSN: 1415-7543 E-ISSN: 1981-9021 http://www.e-publicacoes.uerj.br/index.php/geouerj 


\section{FIGURA 2: BIBLIOTECA DA ESCOLA}

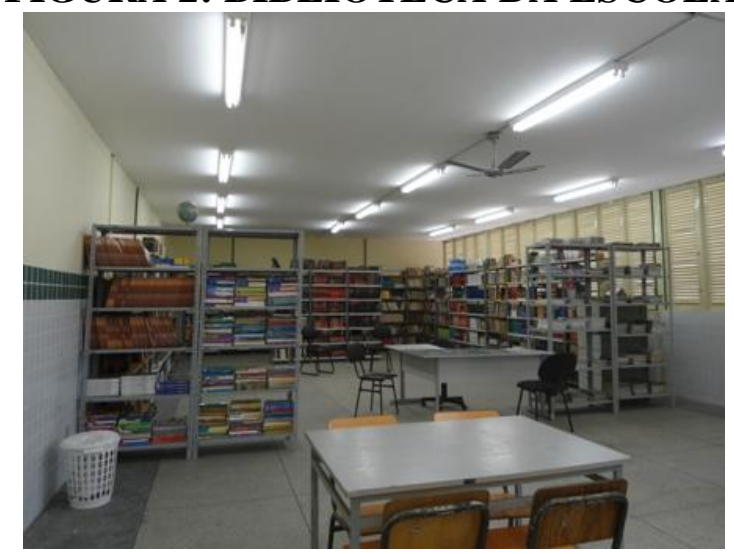

Fonte: Paiva, Viviane. Setembro-2012.

As turmas escolhidas para o desenvolvimento das atividades foram " $3^{\circ}$ ano E" e "3 ano F". As atividades do PIBID nestas turmas se iniciaram no final do mês de agosto de 2012. Durante os meses de setembro e outubro foi aplicado um questionário para identificar o perfil de cada turma, conhecer as deficiências e dificuldades que os alunos têm em relação aos conteúdos da disciplina de Geografia. Após a análise dos questionários, traçou-se um perfil, onde se identificou uma série de informações, entre estes a deficiência dos alunos com relação à cartografia. Diante deste fato, iniciaram-se as atividades de intervenção nas aulas e, junto ao professor supervisor, o projeto começou a ser planejado, desenvolvido para em seguida ser executado.

\subsection{Método}

Baseando-se na ideia de que os alunos já possuem uma noção espacial desenvolvida a partir do senso comum e da sua vivência no espaço, procurou-se construir uma abordagem socioconstrutivista de ensino-aprendizagem, fundamentada na fenomenologia, pois através da cartografia os alunos pensam e representam seu espaço, de acordo com sua percepção conseguindo, assim, desenvolver as atividades propostas.

\subsection{Técnicas}

A metodologia proposta foi composta por etapas:

a) Inicialmente, foi realizada intervenção nas aulas ministradas pelo professor supervisor, com sua anuência, buscando abordar os conteúdos de Cartografia e Geopolítica, oportunidade em que foi feita uma revisão sobre os elementos da cartografia, assim como se tratou a geopolítica na escala geográfica local; 
b) Em sequência, as turmas foram divididas em grupos, de acordo com os bairros em que residem os alunos, oportunidade em que foram solicitadas as informações que deveriam compor o mapa (presença de escolas, saneamento, áreas verdes, prédios e verticalização, pontos de comércio (supermercado, farmácia, padaria);

c) Após o levantamento dos dados, partiu-se para representação através dos mapas, seguida de descrição textual sobre a experiência da produção dos mapas e a representação dos bairros (seu espaço vivido) através de sua percepção.

d) Apresentação dos trabalhos pelos alunos, seguida de discussão dos problemas do cotidiano que afetam os mesmos, já explicitados acima;

e) Por fim, produção de um mural com a exposição dos trabalhos realizados.

\section{RESULTADOS E DISCUSSÕES}

Ao iniciar o projeto havia certo receio quanto à aceitação dos alunos, já que se tratava de algo novo e que requeria interesse, participação e empenho de todos para que os resultados esperados fossem alcançados. Dessa forma, no primeiro dia destinado à implementação do projeto junto ao professor supervisor, apresentou-se os objetivos aos alunos. Em ambas as turmas, surgiram dúvidas quanto à implementação da proposta, mas no decorrer das aulas, estas foram sanadas.

No segundo momento, quando foi repassada aos alunos a tarefa de buscar conhecimentos acerca dos pontos que deveriam ser representados nos mapas, em ambas as turmas, alguns alunos acabaram por ficar com mais responsabilidades que outros, porém para estimular a participação de todos, foi avisado que, caso apenas um aluno ficasse responsável por esta atividade, este estaria liberado das demais, logo o restante da equipe faria as próximas etapas do trabalho, o que fez com que todos participassem.

Após a coleta dos dados de cada bairro, iniciou-se a construção do mapa de Campina Grande-PB. A partir deste momento, foi possível notar uma forte participação de todos os componentes das equipes, uns queriam desenhar, outros pintar, outros auxiliavam no posicionamento do mapa matriz, etc. A partir deste momento, foi possível notar o quanto o projeto estava sendo importante para os alunos e que o mesmo teria êxito, apesar das dificuldades. No decorrer das atividades, houve a preocupação de sempre mostrar aos alunos a relação entre as atividades que estavam sendo realizadas e 
o conhecimento que eles poderiam adquirir a partir da experiência, usando subsídios de seu aprendizado anterior, em consonância com o pensamento de Barbosa (2012):

É importante frisar aos alunos o impacto subjetivo e, portanto, ideológico dos mapas, neste sentido, educar cartograficamente significa educá-los via linguagem geográfica por meio de suas categorias e conceitos. Os discursos ideológicos cartografados serão identificados e analisados por alunos atentos e que tenham subsídios teóricos para entender e apontar tais elementos. Ensinar Geografia é potencializar uma linguagem específica que permite ir além do mundo, a cartografia histórica é uma dessas ferramentas que potencializam o conhecimento e o avançar intelectual e prático do aluno no mundo (ibidem, p.17).

As preocupações existentes não eram direcionadas apenas à compreensão dos alunos em relação ao cumprimento das atividades, infelizmente ocorreram alguns impasses, como por exemplo, a escola não dispunha de mesas adequadas para a realização de uma atividade deste porte, envolvendo o uso de material específico para a atividade, mas os alunos, com muita criatividade, irreverência e improvisação, procuraram vencer os obstáculos, conforme representação através da Figura 3.

\section{FIGURA 3: INICIO DAS ATIVIDADES, DIFICULDADES NA CONSTRUÇÃO DOS MAPAS.}

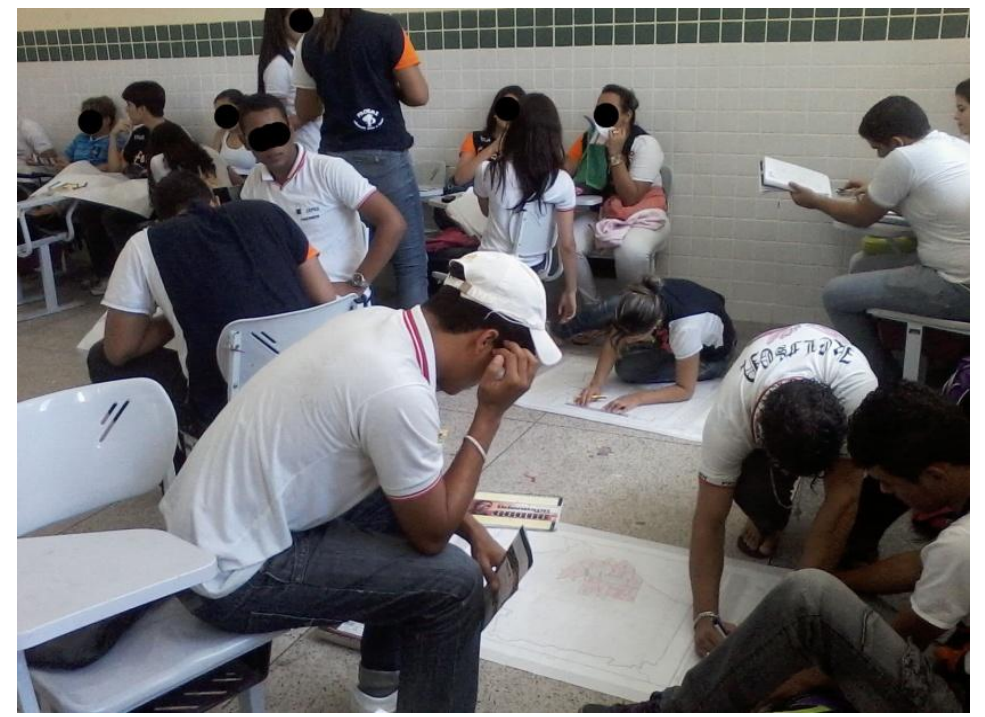

Fonte: Paiva, Viviane. Setembro-2012. 
Após reproduzirem o mapa da cidade, os alunos colocaram os elementos cartográficos e ressaltaram os traços da imagem para ficar mais nítida. Em todas as etapas, foi possível notar a atenção de todos os participantes, até mesmo os alunos que eram mais dispersos se mostraram participativos e envolvidos com a atividade.

$\mathrm{Na}$ etapa seguinte, partiu-se para a inserção das imagens que representavam as informações coletadas pelos alunos a respeito da organização espacial de cada bairro (Figura 4). Neste momento, as equipes puderam interagir e comparar os diferentes elementos encontrados em cada bairro e como eles se organizavam percebendo, assim, como a organização espacial da cidade de Campina Grande diverge entre cada bairro.

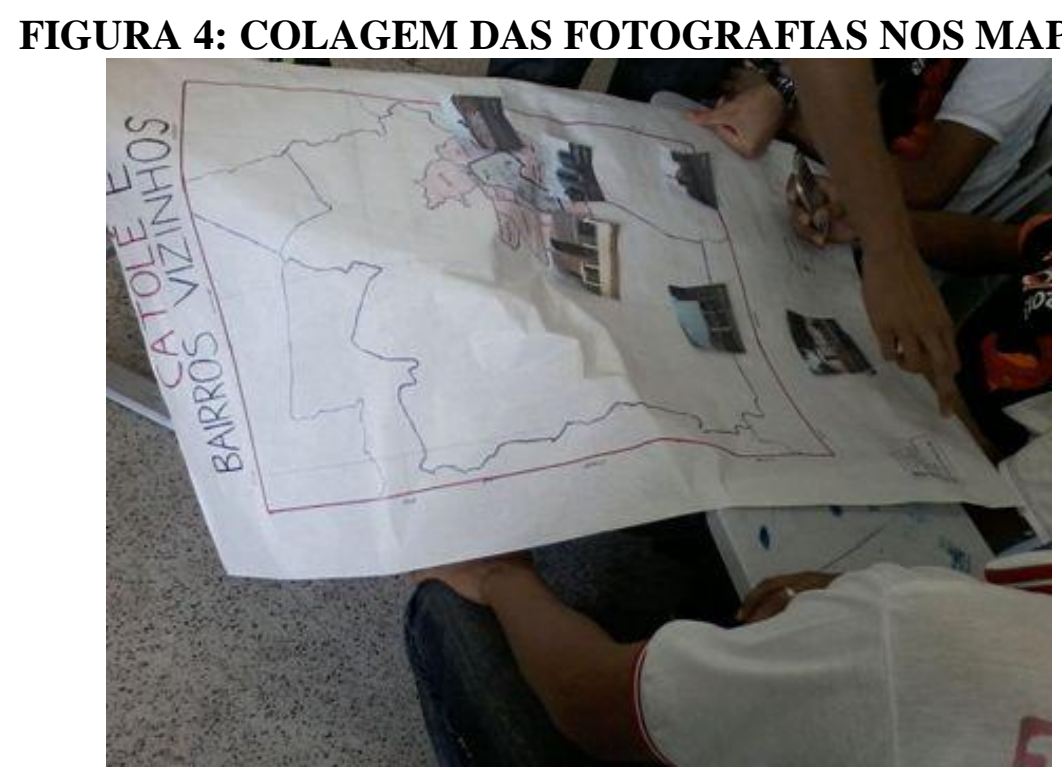

Fonte: Paiva, Viviane. Setembro-2012.

Para finalizar a etapa de construção dos mapas, foi explicado aos alunos a importância da legenda e esta foi acrescentada ao mapa. Para que o mapa tivesse uma base sólida, à folha de papel manteiga, foi anexada a uma folha de isopor (Figura 5).

\section{FIGURA 5: ANEXAR À FOLHA DE PAPEL MANTEIGA AO ISOPOR.}




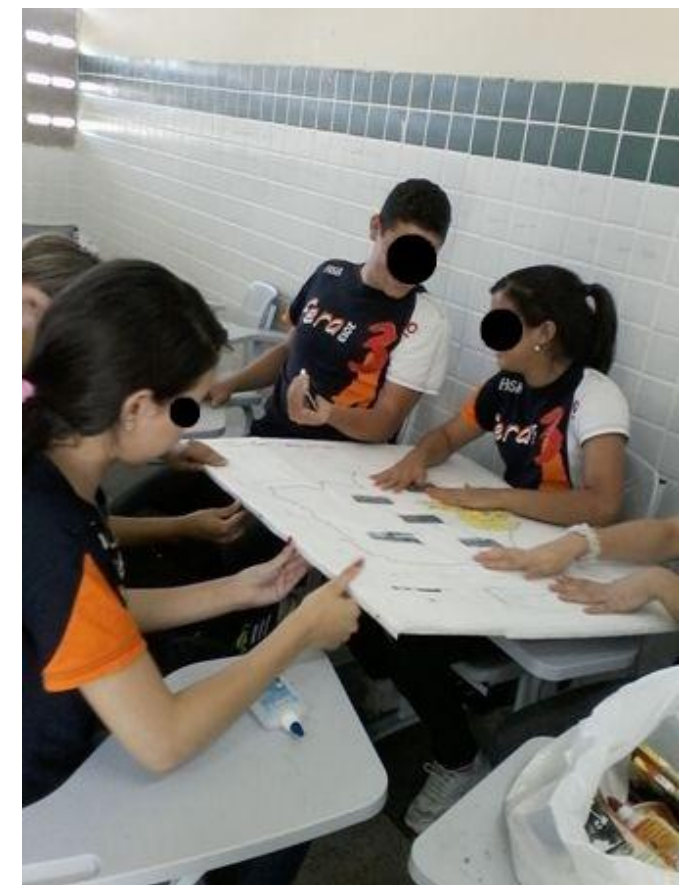

Fonte: Paiva, Viviane. Setembro-2012.

Como parte final das atividades, os alunos puderam fazer uma pequena apresentação acerca da estrutura de cada bairro (Figuras 6 e 7).

FIGURA 6: APRESENTAÇÃO DO MAPA, ALUNOS DO $3^{\circ}$ ANO E.

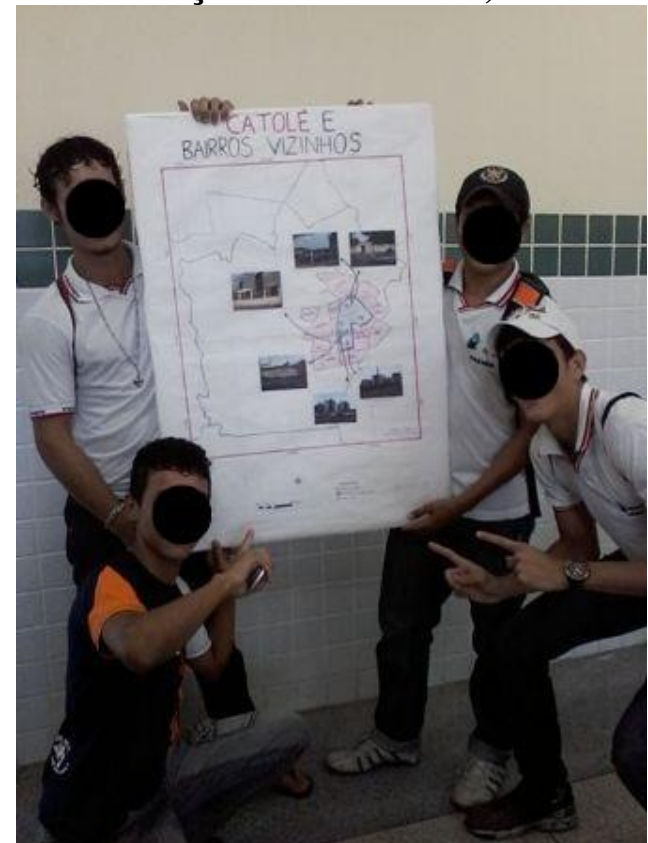

Fonte: Paiva, Viviane. Setembro-2012.

FIGURA 7: APRESENTAÇÃO DO MAPA, ALUNOS DO $3^{\circ}$ ANO F. 


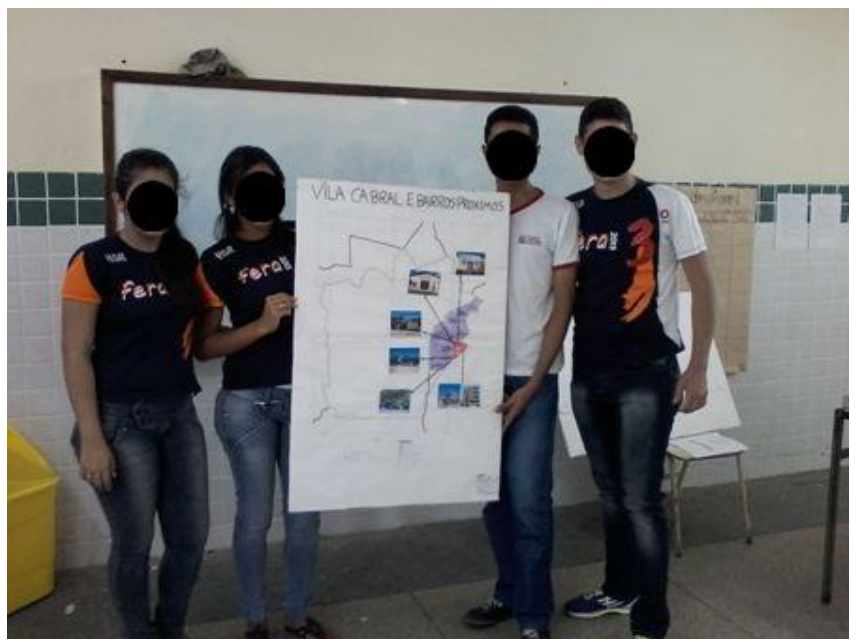

Fonte: Paiva, Viviane. Setembro-2012.

Ao final da atividade, os alunos tiveram a oportunidade de expressar a opinião quanto à experiência proporcionada pelo projeto de intervenção do PIBID/CAPES/UEPB, Subprojeto de Geografia. Dentre os relatos, apresentam-se:

"Essa foi uma das atividades que eu mais gostei de fazer aqui na escola, foi algo diferente, que me fez aprender mais sobre minha cidade" (Aluno X, $3^{\circ}$ “E”).

"Gostei muito desse projeto, pois graças a vocês, pude aprender um pouco sobre cartografia" (Aluno Y, $3^{\circ}$ "F").

O que mais chamou atenção foi que, ao iniciar o projeto, quando foi apresentado o mapa de Campina Grande, 95\% dos alunos ficaram perplexos, pois mesmo sendo alunos do $3^{\circ}$ ano do Ensino Médio, nunca haviam visto o mapa da própria cidade.

Com o desenvolvimento do projeto, foi possível notar o quanto a experiência foi válida para os bolsistas e para os alunos que se dispuseram a participar e demonstraram satisfação com a inovação nas aulas a partir das atividades de projeto. Tais resultados estão em consonância com os resultados obtidos por Sales e Silva (2007):

[...] mais do que uma tecnologia e ciência, a Cartografia tem uma vertente artística, sendo o cartógrafo o artista que elabora sua arte (o mapa) de forma a se comunicar diretamente com a sensibilidade do leitor, e foi assim o observado durante as aulas expositivas e práticas da Disciplina Cartografia Temática (ibidem, p. 4).

Geo UERJ. Rio de Janeiro - Ano 16, ${ }^{\circ}$. 25, v.2, $2^{\circ}$ semestre de 2014, pp.108-121

ISSN: 1415-7543 E-ISSN: 1981-9021

http://www.e-publicacoes.uerj.br/index.php/geouerj 
Diante desta visão acerca da cartografia, os alunos conseguiram sentir a emoção, o prazer de construir um mapa. Todo o processo de desenhar, colorir, acrescentar as informações coletadas e as fotografias foi extremamente válido para o aprendizado dos alunos. Constatou-se que a utilização e construção de mapas conceituais enriqueceram a aula, em conformidade com a citação de Falcão (2011).

Estimulando os alunos a raciocinarem para construir conceitos (...) que caracterizem os respectivos conteúdos, comprovando (...) que os mapas conceituais favorecem a aprendizagem significativa, auxiliando os estudantes a fazerem as conexões conceituais enquanto realizam experimentos (ibidem, p. 8).

A partir desta atividade, foi possível estabelecer uma relação entre o ensino de Geografia e o espaço vivido, alcançando um dos objetivos do projeto. Os alunos se dedicaram visivelmente à realização das atividades propostas, despertaram a vontade de conhecer melhor a cidade como um todo, na medida em que apreciaram as informações apresentadas pelos colegas. Adicionalmente, as atividades proporcionaram mostrar um lado da Geografia que os alunos ainda não conheciam, ou seja, eles conseguiram construir o seu próprio conhecimento geográfico e isto mudou a visão deles acerca da Geografia. Resultado semelhante foi também encontrado no trabalho de Goís (2012):

[...] foi possível estimular os alunos a mergulharem na temática cartografia a consequência disso foi o despertar da curiosidade dos discentes pelos espaços da cidade em que eles vivem. Transformando assim a geografia de uma matéria chata, simplória e enfadonha em uma disciplina instigante e apaixonante (ibidem, p. 13).

Os alunos estão abertos para novas experiências, requerendo empenho da parte docente para inovar nas aulas e procurar meios para conquistá-los, para que eles percebam a importância que a Geografia tem, não apenas para adquirir conhecimento escolar, mas como conhecimento para suas experiências de vida, conhecendo melhor o mundo em que habita e compreendendo o significado que suas ações ou a falta delas, como cidadãos atuantes, tem para a sociedade em que vive.

\section{CONSIDERAÇÕES FINAIS}


Após o término das atividades, foi possível constatar que o trabalho obteve resultados positivos, observou-se a interação entre os alunos, os bolsistas e o projeto. Com o ciclo de apresentações e o compartilhamento de experiências durante as atividades, estabeleceu-se uma troca de conhecimentos acerca do espaço estudado, comum à realidade de todos os envolvidos, a Cidade de Campina Grande. Durante todas as etapas da construção dos mapas, as turmas se mostraram participativas e interessadas em cumprir as tarefas sugeridas. Em relação ao conhecimento cartográfico, foi possível notar que houve uma melhora significativa no aprendizado.

Por conta dos obstáculos que o ensino como um todo enfrenta, algumas vezes há o receio de desenvolver-se um projeto ou até mesmo uma aula diferente, mas mesmo diante das dificuldades o professor não pode desistir ou se abater. É preciso perseverança, pois atualmente o acesso aos materiais didático pedagógicos é bem maior, na maioria das vezes, levar algo simples, porém diferente já engrandece a aula.

Um mapa, uma música, um vídeo curto, são recursos que podem ser usados. As ideias de atividades ou projetos devem ser executadas, pois é necessário cativar os alunos, pois, a cada dia, o mundo fora das paredes da escola se torna mais atrativo, as novas tecnologias seduzem os alunos, mas é possível usá-las a favor do estudo, da escola. Com algumas complementações metodológicas é possível incentivar o aluno para a aprendizagem, possibilitando uma maior compreensão do espaço vivido.

Levando em consideração o ensino nas escolas públicas do país, o PIBID tem sido uma alternativa inovadora no ensino, pois proporciona que algumas turmas possam participar de experiências diferentes, possibilitando que o professor supervisor junto com os bolsistas desenvolva atividades que busquem preencher as expectativas dos alunos em relação ao ensino, buscando contribuir para o processo ensino-aprendizagem, utilizando recursos que estão ao alcance de todos os alunos das escolas públicas.

\section{AGRADECIMENTOS}

As autoras agradecem o apoio concedido, mediante bolsas, efetuado pela Coordenação de Aperfeiçoamento de Pessoal de Nível Superior - CAPES, através do Programa Institucional de Bolsas de Iniciação à Docência - PIBID. 


\section{REFERÊNCIAS}

ALMEIDA, R. D. de. PASSINI, E. Y. O Espaço geográfico: ensino e representação. $15^{\mathrm{a}}$. Ed. São Paulo: Contexto. 2006.

BARBOSA, T. O Ensino de Geografia pela Cartografia Histórica. Geosaberes, v. 1, n. 2, Dezembro/2010.

BRASIL. Parâmetros Curriculares Nacionais. Geografia. Secretaria de Educação Fundamental. Brasília. Ministério da Educação. 2001.

CALLAI, H. C. Estudar o lugar para compreender o Mundo. In: CASTROGIOVANNI, A. C. (org.). Ensino de Geografia: práticas e textualizações no cotidiano. Porto Alegre: Mediação, 2000.

CAVALCANTI, L. de S. Geografia escolar e a cidade: ensaios sobre o ensino de Geografia para a vida urbana cotidiana. Campinas: Papirus, 2008.

CAVALCANTI, L. de S. Ensino de Geografia e diversidade: construção de conhecimentos geográficos escolares e atribuição de significados pelos sujeitos do processo de ensino. IN: CASTELLAR, S. (org.). Educação geográfica: teorias e práticas. $2^{a}$. ed. São Paulo: Contexto. 2007.

FALCÃO, P. H. de B. O ensino da disciplina metodologia científica através de mapas conceituais e do diagrama do Conhecimento. IN: V colóquio Internacional Educação e Contemporaneidade. Anais... São Cristovão- SE/ Brasil, 21 a 23 de setembro de 2011.

FRANCISCHETT, M. N. A cartografia no ensino-aprendizagem da Geografia. Disponível em: www.bocc.ubi.pt. Acesso em: 10/04/2013

GADOTTI, M. Escola cidadã, cidade educadora: projetos e práticas em processo. V Fórum de Educação CEAP. Salvador. Abril de 2003.

GÓIS, R. A. D. Brincando com a Cartografia: mapeando a cidade. Geosaberes, Fortaleza, v. 3, n. 6, p. 79-92, jul. / dez. 2012.

HOFFMANN, J. O Jogo do contrário em avaliação. Porto Alegre: Mediação, 2007.

HOFfMANN, J. Avaliação Mito e Desafio Uma Perspectiva Construtivista. 24 ${ }^{a}$. Ed. Porto Alegre: Mediação, 1988.

KAERCHER, N. A. O Gato Comeu a Geografia Crítica? Alguns Obstáculos a superar no Ensino-Aprendizagem de Geografia. In: PONTSCHUKA, N. N.; OLIVEIRA, A. B. (org.). Geografia em Perspectiva. $3^{\text {a }}$ ed. São Paulo: Contexto, 2006.

LACOSTE, Y. A Geografia, isso serve, em primeiro lugar, para fazer a guerra. Campinas, SP: Papirus, 1988. 
MOREIRA, R. Pensar e ser em Geografia: ensaios de historia, epistemologia e ontologia do espaço geográfico. São Paulo: Contexto, 2007.

OLIVEIRA, L. Estudo Metodológico e Cognitivo do Mapa. IN: ALMEIDA, R. D. de. (org.). Cartografia Escolar. 2 ${ }^{\mathrm{a}}$ Ed. São Paulo: Contexto, 2010.

PASSINI, E. Y.; PASSINI, R.; MALYSZ, S. T. (Org.). Práticas de ensino de Geografia e Estágio Supervisionado. São Paulo: Contexto, 2007.

PIMENTA, S. G. et al. Estágio e Docência. São Paulo: Editora Cortez. Ed. 6a 2011.

PONTUSCHKA, N. N.; et. Al. Para ensinar e aprender Geografia. São Paulo: Cortez, 2009.

SALES, J. J. G.; SILVA, R. M. da. O ensino de cartografia temática como um instrumento perceptivo no ensino de Geografia. IN: $X$ Encontro de Iniciação á Docência. Anais... João Pessoa - PB/ Brasil, 09 a 11 de maio de 2007.

SANTOS, M. Metamorfoses do Espaço Habitado: Fundamentos Teóricos e Metodológicos da Geografia. Hucitec. São Paulo. 1988.

SELBACH, S. (Supervisão geral). Geografia e Didática. Petrópolis, RJ: Vozes, 2010.

SILVA, L. G. Jogos e situações problema na construção das noções de lateralidade, referências e localização espacial. In: CASTELLAR, S. (Org.). Educação geográfica: teorias e práticas. 2. ed. São Paulo: Contexto, 2006, p.137-156.

SIMIELLI, M. E. O mapa como meio de comunicação e a alfabetização cartográfica. In: ALMEIDA, R. D.de (Org.). Cartografia escolar. São Paulo: Contexto, 2007, p. 71- 94.

SOUZA, D. da C.; RIOS, R. B. Ensino e Aprendizagem da Cartografia no Ensino Fundamental: dilemas entre a Teoria e a Prática. Artigo apresentado no $10^{\circ}$ ENPEG, Porto Alegre, 2009.

Artigo recebido para publicação em março de 2014.

Artigo aceito para publicação em novembro de 2014. 